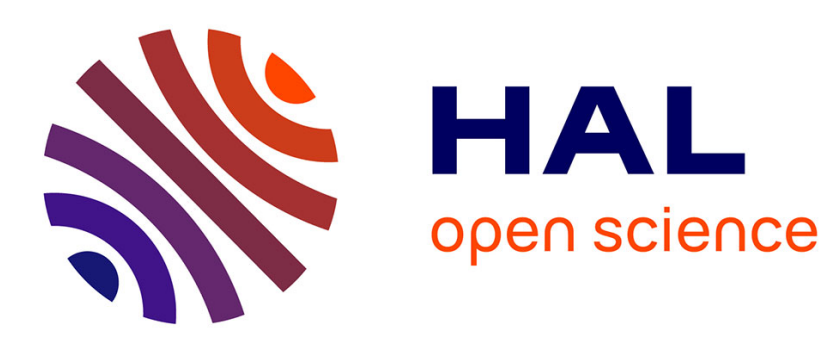

\title{
Transient Isotopic Studies and Microkinetic Modeling of CO Methanation over Nickel Catalysts
}

\author{
D. Lorito, P. Fongarland, Y. Schuurman
}

\section{To cite this version:}

D. Lorito, P. Fongarland, Y. Schuurman. Transient Isotopic Studies and Microkinetic Modeling of CO Methanation over Nickel Catalysts. Industrial and engineering chemistry research, 2021, 60 (18), pp.6698-6705. 10.1021/acs.iecr.0c05885 . hal-03252868

\section{HAL Id: hal-03252868 \\ https://hal.science/hal-03252868}

Submitted on 1 Oct 2021

HAL is a multi-disciplinary open access archive for the deposit and dissemination of scientific research documents, whether they are published or not. The documents may come from teaching and research institutions in France or abroad, or from public or private research centers.
L'archive ouverte pluridisciplinaire HAL, est destinée au dépôt et à la diffusion de documents scientifiques de niveau recherche, publiés ou non, émanant des établissements d'enseignement et de recherche français ou étrangers, des laboratoires publics ou privés.

\section{(c)(1)}

Distributed under a Creative Commons Attribution| 4.0 International License 


\title{
Transient Isotopic Studies and Microkinetic Modeling of CO Methanation over Nickel Catalysts
}

\author{
Davide Lorito, Pascal Fongarland, and Yves Schuurman*
}

\begin{abstract}
The methanation of $\mathrm{CO}$ over a 20 wt $\% \mathrm{Ni} / \mathrm{Al}_{2} \mathrm{O}_{3}$ catalyst was studied with different transient experiments. $\mathrm{CO}$ dissociation was found to be reversible and faster than the formation of methane. SSITKA experiments showed that two pools of surface intermediates lead to the formation of methane. The transient experiments could be adequately described by a microkinetic model based on two distinct adsorbed $\mathrm{CO}$ species. One $\mathrm{CO}$ species proceeds through direct dissociation, and the other, through hydrogen assisted dissociation to a common $\mathrm{CH}^{*}$ intermediate that leads to methane. The model is consistent with literature DFT studies that show that the direct CO dissociation occurs over edge or step sites and hydrogen assisted dissociation occurs over terrace sites.
\end{abstract}

\section{INTRODUCTION}

$\mathrm{CO}$ methanation over nickel supported catalysts has great potential for the production of synthetic natural gas from syngas generated from coal, biomass, or waste. ${ }^{1,2}$ Nickel supported catalysts can also be used to produce longer chain hydrocarbons by Fischer-Tropsch (FT) synthesis. ${ }^{3}$ The mechanism of CO hydrogenation over transition metals is still debated in the literature. ${ }^{4}$ In the case of $\mathrm{CO}$ hydrogenation over nickel, some mechanistic studies propose "enol-like" intermediates, while other studies suggest a carbide mechanism based on direct $\mathrm{CO}$ dissociation. ${ }^{5-17}$ In the Fischer-Tropsch literature the direct and hydrogen-assisted $\mathrm{CO}$ dissociation are still being strongly debated, supported by DFT studies. ${ }^{18-22}$

The reactive intermediates, like the enol species, are present on the surface at very small concentrations. In situ spectroscopic methods such as FTIR or DRIFTS are not sensitive enough to identify these surface species. Although methoxy and formate species are observed by in situ FTIR, they can be located on the support and often are considered to be spectators. In order to distinguish reactive intermediates from spectators, dynamic experiments are necessary and most spectroscopic cells are not very well suited for transient operation due to the presence of dead volumes and the difficulty to operate in the absence of temperature and concentration gradients. This is especially the case for exothermic reactions like CO methanation.

Steady State Isotopic Transient Kinetic Analysis (SSITKA) and chemical transient kinetics (CTK) have been used to investigate the kinetics of the methanation over nickel catalysts. $6,7,26-35$ Transient kinetics allow estimating amounts of relevant surface species and kinetic constants and decouple these two quantities. In the SSITKA technique, the reactant is replaced by its isotopic counterpart, giving a transient response of the isotopically labeled reactants and products, while preserving steady-state operation. CTK switches between different reactant concentrations, while going from one steady state toward another one. Information on the reaction intermediates can be obtained by carefully tracking the balance of $\mathrm{C}, \mathrm{H}, \mathrm{O}$ or the isotopically labeled element as a function of time. ${ }^{7,26,27,29}$ While transient methods lead to better insights into the reaction mechanism, the modeling of the data is a much more complex task than for steady-state experiments. The steady-state hypothesis is no longer valid, and the continuity equations for surface intermediates need to be solved explicitly. This will lead to a much larger number of kinetic parameters to be estimated. ${ }^{36-38}$

An often common observation in SSITKA studies of CO hydrogenation over transition metals is the presence of at least two pools of intermediates for the production of methane. ${ }^{35,39-44}$ However, few studies address the nature of these intermediates. In this paper we explore if the combination of the direct and hydrogen-assisted CO dissociation is compatible with these two intermediates by developing a microkinetic model based on SSITKA and CTK experiments.

\section{EXPERIMENTAL SECTION}

Catalyst. All experiments were performed over a welldispersed $20 \mathrm{wt} \% \mathrm{Ni} / \mathrm{Al}_{2} \mathrm{O}_{3}$ catalyst. Catalyst characterization was reported in ref 45 . The BET surface area was approximately $100 \mathrm{~m}^{2} / \mathrm{g}$. A mean nickel particle size of $5 \mathrm{~nm}$ 
was observed by Transmission Electron Microscopy. From hydrogen adsorption experiments, a nickel surface site concentration of $0.68 \mathrm{~mol} / \mathrm{kg}$ was estimated, in line with the mean nickel particle size of $5 \mathrm{~nm}$. Additional nonsteady-state experiments were carried out over a 10 wt $\% \mathrm{Ni} / \mathrm{SiC}$ catalyst with a BET surface area of $30 \mathrm{~m}^{2} / \mathrm{g}$ and a mean nickel particle size of $6 \mathrm{~nm}$.

Catalyst Testing. Steady-state, nonsteady state, and SSITKA experiments were performed in a fixed-bed reactor (I.D. $=7 \mathrm{~mm}$ ) filled with $0.2 \mathrm{~g}$ of catalyst diluted with $\mathrm{SiC}$. The catalyst pellet size was in the range $100-200 \mu \mathrm{m}$. A thermocouple was located inside the catalyst bed. The reactor was $20 \mathrm{~cm}$ long, but the catalyst bed was approximately $1.5 \mathrm{~cm}$. The reactor volume before the catalyst bed was filled with silicon carbide particles. After the catalyst bed the reactor diameter was reduced to $3 \mathrm{~mm}$. The catalyst bed void fraction was estimated at 0.45 . The $\mathrm{Ni}$ catalyst was reduced in situ at $500{ }^{\circ} \mathrm{C}$ for $10 \mathrm{~h}$, with a temperature increasing rate of $1{ }^{\circ} \mathrm{C} /$ min. A mixture of $20 \% \mathrm{H}_{2} / 80 \% \mathrm{Ar}$ with a flow rate of $100 \mathrm{smL} /$ min was used. After the reduction the catalyst was exposed to the reaction mixture of $15 \% \mathrm{CO} / 60 \% \mathrm{H}_{2} / 25 \% \mathrm{Ar}$ with a flow rate of $100 \mathrm{smL} / \mathrm{min}$ for at least $24 \mathrm{~h}$. Switches between reaction mixtures were realized using a two-position four-way Valco-valve. Krypton was added to analyze the gas hold up. The effluents were monitored by an online INFICON quadrupole mass spectrometer. All the experiments were performed at $210{ }^{\circ} \mathrm{C}$, a pressure of $1.2 \mathrm{bar}$, and a $\mathrm{H}_{2} / \mathrm{CO}$ ratio equal to 4 . The $\mathrm{CO}$ conversion under these conditions amounted to approximately $3 \%$, and the only observed products were methane and water; no carbon dioxide or higher hydrocarbons were observed in any significant amount.

SSITKA Data Treatment. From the integration of the transient response, the concentration, $N_{i}(\mathrm{~mol} / \mathrm{kg})$, of reversibly adsorbed $\mathrm{CO}^{*}$ and partly dissociated $\mathrm{CO}^{*}$ as well as active $\mathrm{CH}_{x}{ }^{*}$ and/or $\mathrm{COH}_{x}{ }^{*}$ intermediates leading to methane can be calculated by ${ }^{26}$

$$
N_{i}=\frac{1}{W} \int_{0}^{\infty}\left|F_{i}(t)-F_{t r}(\mathrm{t})\right| \mathrm{d} t
$$

where $W$ is the catalyst mass $(\mathrm{kg}), t$ is the time $(\mathrm{s}), F_{i}(t)$ is the time-dependent outlet flow of species $\mathrm{i}(\mathrm{mol} / \mathrm{s})$, and $F_{\mathrm{tr}}(t)$ is the outlet flow of the tracer gas $(\mathrm{mol} / \mathrm{s})$. The surface lifetimes $\tau_{I, r}(\mathrm{~s})$ were calculated $\mathrm{by}^{26}$

$$
\tau_{i, r}=\frac{N_{i}}{R_{i}(\infty)}
$$

where $R_{\mathrm{i}}(\infty)(\mathrm{mol} / \mathrm{s} / \mathrm{kg})$ is the steady-state consumption or production rate.

The "net" surface lifetimes $\tau_{I}(\mathrm{~s})$ are obtained after correcting the average residence time by the inert tracer. $\mathrm{Kr}$ represents the hold-up of the reactor system:

$$
\begin{aligned}
& \tau_{\mathrm{CO}}=\tau_{\mathrm{CO}, r}-\tau_{\mathrm{Kr}, r} \\
& \tau_{\mathrm{Cl}}=\tau_{\mathrm{Cl}}-\frac{1}{2} \tau_{\mathrm{CO}}-\tau_{\mathrm{Kr}, r}
\end{aligned}
$$

In the last equation, which is of empirical nature, the surface lifetime of methane is further corrected for the chromatographic effect of $\mathrm{CO}$ in a plug-flow reactor, as is custom in the literature. $^{26}$

The following compartment models were used to fit the methane decay $(E(t))$ during SSITKA experiments for one pool (eq 5) and two parallel pools (eq 6): ${ }^{35}$

$$
\begin{aligned}
& E(t)=N \exp \left(-\frac{t}{\tau}\right) \\
& E(t)=N_{1} \exp \left(-\frac{t}{\tau_{1}}\right)+\left(1-N_{1}\right) \exp \left(-\frac{t}{\tau_{2}}\right)
\end{aligned}
$$

The derivation of these equations is based on differential conditions and an ideal step response input.

Modeling. The transient model is based on a onedimensional pseudohomogeneous fixed bed reactor, thus assuming no radial and no external and internal mass- and heat transfer limitations. The gas velocity is assumed to be constant. The continuity equations are then given for the gas phase and adsorbed phase respectively as

$$
\begin{gathered}
\varepsilon_{b} \frac{\delta C_{i}}{\delta t}=-u_{s} \frac{\partial C_{i}}{\partial z}+D_{a x, i} \frac{\partial^{2} C_{i}}{\partial z^{2}}-\left(1-\varepsilon_{b}\right) \\
L_{t}\left(k_{a d s, j} P_{i} \theta_{*}-k_{d e s, j} \theta_{i}\right) \\
\frac{\partial \theta_{i}}{\partial t}=\sum_{j} v_{i j} k_{j} P_{i}^{n} \prod_{j^{\prime}} \theta^{m}
\end{gathered}
$$

where $L_{\mathrm{t}}$ is the number of active sites per catalyst volume $\left(\mathrm{mol} / \mathrm{m}^{3}{ }_{\text {cat }}\right), u_{\mathrm{s}}$ the superficial gas velocity $\left(\mathrm{m}_{\mathrm{r}} / \mathrm{s}\right), D_{\mathrm{ax}}$ the axial diffusion coefficient $\left(\mathrm{m}_{\mathrm{g}}{ }^{3} / \mathrm{m}_{\mathrm{r}} / \mathrm{s}\right), \varepsilon_{\mathrm{b}}$ the bed void fraction $\left(\mathrm{m}_{\mathrm{f}}{ }^{3} /\right.$ $\left.\mathrm{m}_{\mathrm{r}}^{3}\right), C_{\mathrm{i}}$ the gas phase concentration of each species $\left(\mathrm{mol} / \mathrm{m}_{\mathrm{f}}^{3}\right)$, $P_{\mathrm{i}}$ the partial pressure of each species (bar), $k_{\mathrm{ads}, \mathrm{j}}$ the adsorption constant for the gas phase species $\left(\operatorname{bar}^{-1} \mathrm{~s}^{-1}\right)$, $k_{\text {des,j }}$ the desorption constant for the gas phase species $\left(\mathrm{s}^{-1}\right)$, and $z$ the reaction axial coordinate $(\mathrm{m})$.

The following initial and boundary conditions are applied for all gas phase species $\mathrm{i}$ :

$$
\begin{aligned}
& t=0 \wedge 0 \leq z \leq L: C_{i}=0 \wedge \theta_{i}(z)=0 \\
& t>0 \wedge z=0: C_{i}=C_{i}^{0}\left(\frac{1-\exp (-A t)}{1+\exp (-A t)}\right) \\
& t>0 \wedge z=L: \frac{\mathrm{d} C_{i}}{\mathrm{~d} t}=0
\end{aligned}
$$

where $L$ is the reactor length $(m)$. This set of partial differential equations is transformed into a set of ordinary differential equations by the methods of lines and integrated numerically using the ODEPACK library. ${ }^{46}$ The axial dispersion coefficient was calculated by the well-known correlation given in ref 47.

The reaction kinetics were calculated by using the law of mass action. This implies that the exponents $n$ and $m$ in eq 8 correspond to the number of species involved in each elementary step given in Table 2, except for step 1a which was considered to be first order, as Derrouiche and Bianchi ${ }^{48}$ observed similar sorption kinetics for linear and bridged carbonyl species. Thus, the rate for step $1 \mathrm{a}$ in Table 3 is calculated as

$$
r_{1 a}=\overrightarrow{k_{1 a}} P_{C O} \theta_{v}-\overleftarrow{k_{1 a}} \theta_{C O * *}
$$

Regression analysis based on a Marquardt-Levenberg algorithm including statistical analysis was used to estimate the kinetic parameters. ${ }^{49,50}$ The $\mathrm{Kr}$ tracer was fitted first to estimate the value of the constant $\mathrm{A}\left(9.9 \mathrm{~s}^{-1}\right)$ in eq 10. For the SSITKA experiments, the outlet flows of ${ }^{12} \mathrm{CO}$ and ${ }^{12} \mathrm{CH}_{4}$ were 

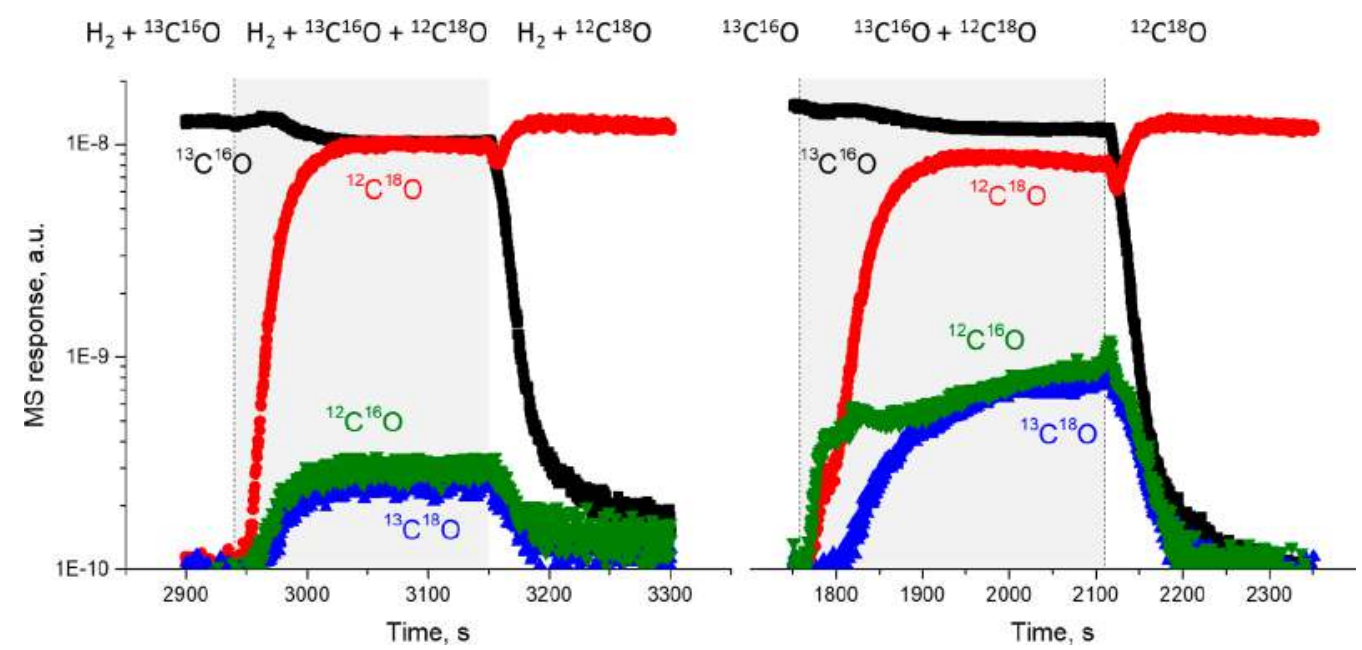

Figure 1. Isotopic scrambling experiments over $20 \mathrm{wt} \% \mathrm{Ni} / \mathrm{Al}_{2} \mathrm{O}_{3}$ in the presence (left) and absence (right) of hydrogen.

used in the objective function, while, for the nonsteady-state experiments, the outlet flows of $\mathrm{CO}, \mathrm{CH}_{4}$, and $\mathrm{H}_{2} \mathrm{O}$ were used.

To check the intrinsic reaction conditions during the reforming experiments the appropriate criteria were evaluated by using the EUROKIN spreadsheet for assessment of transport limitations in gas-solid fixed beds. ${ }^{51}$ The steadystate $\mathrm{CO}$ consumption rate at $210{ }^{\circ} \mathrm{C}$ of $0.018 \mathrm{~mol} / \mathrm{kg} / \mathrm{s}$ was used. The results are reported in Table S1. The criteria indicated the absence of heat and mass transfer limitations.

Campbell's degree of rate control (DRC) was applied to the methane formation at steady state. ${ }^{52}$ This method is used in microkinetic models to evaluate the degree to which reaction steps are rate-controlling. This is accomplished by increasing both forward and reverse rate constants for the specific step and calculating the resulting fractional increase in the overall rate, as expressed by the following equation:

$$
\mathrm{DRC}=\frac{k_{i}}{r}\left(\frac{\partial r}{\partial k_{i}}\right)_{k_{j \neq i}, K_{i}}=\left(\frac{\partial \ln r}{\partial \ln k_{i}}\right)_{k_{j \neq i}, K_{i}}
$$

where the partial derivative is taken holding constant the rate constants, $k_{j}$, for all other steps $j \neq i$ and the equilibrium constant, $K_{i}$, for step $i$. The larger the value of $\mathrm{DRC}_{i}$ is for a given step, the more the influence its rate constant has on the overall reaction rate $r$. A positive value indicates that increasing $k_{i}$ will increase the net rate $r$. A negative value indicates the opposite; such steps are inhibition steps.

\section{RESULTS}

Isotopic Exchange Experiments. Figure 1 shows the ${ }^{12} \mathrm{C}^{16} \mathrm{O}$ and ${ }^{13} \mathrm{C}^{18} \mathrm{O}$ responses from a mixture of ${ }^{12} \mathrm{C}^{18} \mathrm{O}$ and ${ }^{13} \mathrm{C}^{16} \mathrm{O}$ in both the presence and absence of hydrogen (Figure 1). In both cases equal amounts of ${ }^{12} \mathrm{C}^{16} \mathrm{O}$ and ${ }^{13} \mathrm{C}^{18} \mathrm{O}$ are formed, with a lower amount of both products in the presence of hydrogen, due to the fact that part of the adsorbed $\mathrm{CO}$ species will react with hydrogen to form methane. The early ${ }^{12} \mathrm{C}^{16} \mathrm{O}$ response in the absence of hydrogen might be an experimental artifact, amplified by the logarithmic scale of Figure 1. In both the presence and absence of hydrogen, $\mathrm{CO}$ dissociates reversibly over the nickel catalyst. The disappearance rate of ${ }^{12} \mathrm{C}^{16} \mathrm{O}$ and ${ }^{13} \mathrm{C}^{18} \mathrm{O}$, when removing ${ }^{13} \mathrm{C}^{16} \mathrm{O}$ from the feed, is rather similar for both cases, characterized by time constants of 25 and $30 \mathrm{~s}$ in the presence and absence of hydrogen, respectively.

SSITKA Experiments. Figure 2 shows the $\mathrm{CO}$ and methane responses upon a switch from ${ }^{12} \mathrm{CO} / \mathrm{H}_{2}$ to ${ }^{13} \mathrm{CO} /$

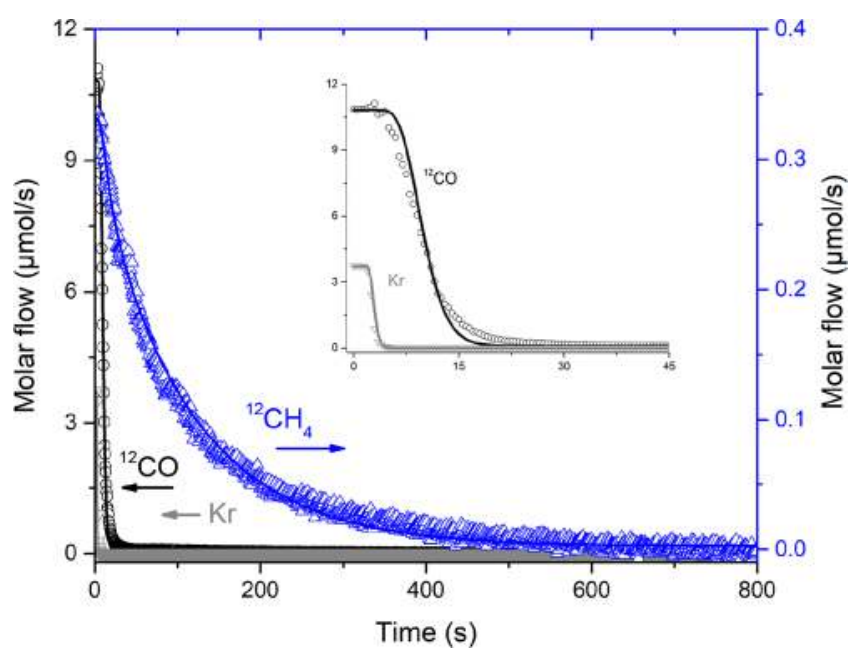

Figure 2. SSITKA experiments for a switch of $15 \%{ }^{12} \mathrm{CO} / 60 \% \mathrm{H}_{2} /$ $20 \% \mathrm{Ar} / 5 \% \mathrm{Kr}$ to $15 \%{ }^{13} \mathrm{CO} / 60 \% \mathrm{H}_{2} / 25 \%$ Ar over 20 wt $\% \mathrm{Ni} / \mathrm{Al}_{2} \mathrm{O}_{3}$ at $210{ }^{\circ} \mathrm{C}$. Symbols are experimental data; lines model to microkinetic model simulation. The inset serves to better visualize the $\mathrm{Kr}$ and ${ }^{12} \mathrm{CO}$ transient responses.

$\mathrm{H}_{2}$ at $210{ }^{\circ} \mathrm{C}$. A symmetric upward response was observed for the 13 carbon labeled components, although the noise-tosignal ratio was higher. A delay in the $\mathrm{CO}$ response with respect to the $\mathrm{Kr}$ tracer can be noticed. This is due to the reversible adsorption of $\mathrm{CO}$ on the nickel surface. The methane response is even further delayed and decreases slowly. Table 1 summarizes the residence times and surface coverages estimated from the ${ }^{12} \mathrm{CO} / \mathrm{H}_{2}$ SSITKA experiments.

Table 1. Surface Amounts and Coverages of $\mathrm{CO}_{\text {ads }}$ and $\mathrm{C}_{1, \mathrm{ads}}$ Based on the Integration of the Transients Shown in Figure 2 with $N_{\mathrm{s}}=0.68 \mathrm{~mol}_{\mathrm{Ni}} \cdot \mathrm{kg}_{\mathrm{cat}}{ }^{-1}$

$\begin{array}{cccccc}\tau_{\mathrm{CO}}(\mathrm{s}) & \tau_{\mathrm{C} 1}(\mathrm{~s}) & N_{\mathrm{CO}}(\mathrm{mol} / \mathrm{kg}) & N_{\mathrm{C} 1}(\mathrm{~mol} / \mathrm{kg}) & \Theta_{\mathrm{CO}} & \Theta_{\mathrm{CHx}} \\ 8 & 99 & 0.44 & 0.16 & 0.65 & 0.23\end{array}$


The $N_{\text {CO }}$ corresponds to surface species that desorb as CO, which might contain species that have been dissociated on the surface, as the $\mathrm{CO}$ adsorption is reversible. The $N_{\mathrm{C} 1}$ species correspond to $\mathrm{CH}_{x}$ species leading to the formation of methane. Note that $\mathrm{CO}$ scrambling $(t=28 \mathrm{~s})$ is faster than the formation of methane $(t=100 \mathrm{~s})$, consistent with the fact that $\mathrm{CO}$ dissociation is not the rate-limiting step.

The rate of methane formation was further inspected by tracing the ${ }^{12} \mathrm{CH}_{4}$ decay on a semilog plot, as shown in Figure 3. The decay rate, and therefore also the rate of methane

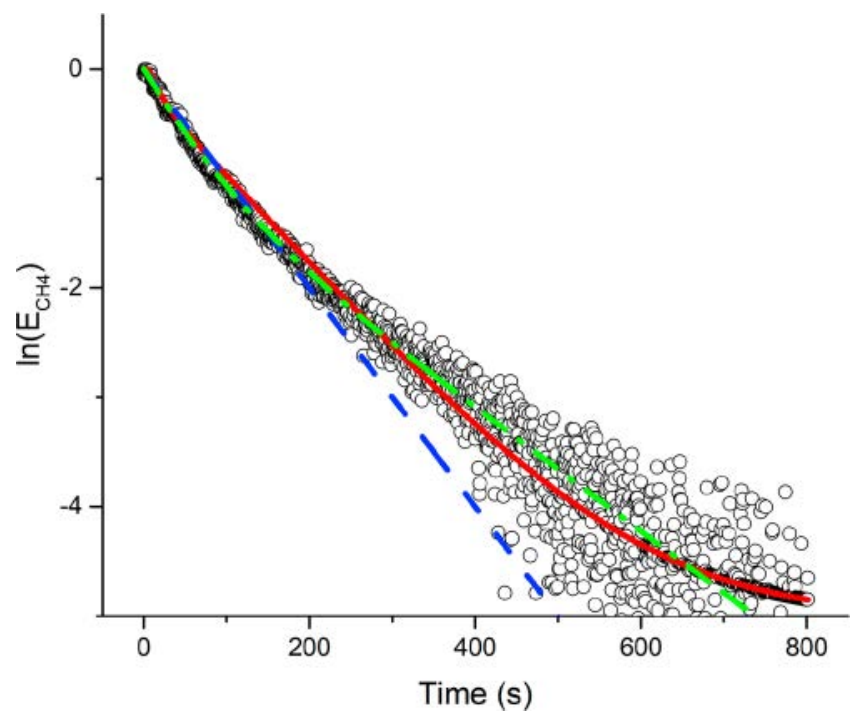

Figure 3. Decay of ${ }^{12} \mathrm{CH}_{4}$ normalized response during SSITKA experiments for a switch of $15 \%{ }^{12} \mathrm{CO} / 60 \% \mathrm{H}_{2} / 20 \% \mathrm{Ar} / 5 \% \mathrm{Kr}$ to $15 \%{ }^{13} \mathrm{CO} / 60 \% \mathrm{H}_{2} / 25 \%$ Ar over 20 wt $\% \mathrm{Ni} / \mathrm{Al}_{2} \mathrm{O}_{3}$ at $210{ }^{\circ} \mathrm{C}$. Symbols are experimental data; lines correspond to eq 5 (blue dashed line) and eq 6 (green dashed dotted line), to microkinetic mode (red full line).

formation as SSITKA responses are symmetric, is downward convex, indicating a parallel formation or a buffer step involving two species. Figure 3 also shows the calculated rates for a single pool $\left(\tau_{\mathrm{C} 1}=100 \mathrm{~s}\right)$ and a two-pool parallel model. $^{35}$ The parallel pool model describes the data adequately with the parameters reported in Table 2 . One pool of $57 \%$ of the $\mathrm{N}_{\mathrm{C} 1}$ species has a characteristic time of $58 \mathrm{~s}$, while the other $43 \%$ has a characteristic time of $178 \mathrm{~s}$.

Table 2. Parameter Estimates from Regression Analysis of Equation 6 to the Normalized Decay of ${ }^{12} \mathrm{CH}_{4}$ (Shown in Figure 3)

\begin{tabular}{ccc}
$\mathrm{N}_{1}$ & $\tau_{1}(\mathrm{~s})$ & $\tau_{2}(\mathrm{~s})$ \\
0.57 & 58 & 178 \\
\hline
\end{tabular}

Nonsteady-State Experiments. The catalyst was initially reduced under a $\mathrm{H}_{2} / \mathrm{He}\left(60 \mathrm{vol} \% / 40\right.$ vol \%) flow at $400{ }^{\circ} \mathrm{C}$, and then the reactor temperature was lowered to $210{ }^{\circ} \mathrm{C}$. Figure 4 shows the transient responses when switching from the $\mathrm{H}_{2} / \mathrm{He}(60 \mathrm{vol} \% / 40 \mathrm{vol} \%)$ feed to a ${ }^{12} \mathrm{CO} / \mathrm{H}_{2} / \mathrm{Ar}(15 \mathrm{vol}$ $\% / 60$ vol \%/25 vol \%) mixture. At the moment of the switch, gas phase hydrogen is released. An initial "overshoot" in the methane response is observed, followed by a steady state production. On the other hand, the water formation is strongly delayed. This is due to a retention of the water by the alumina

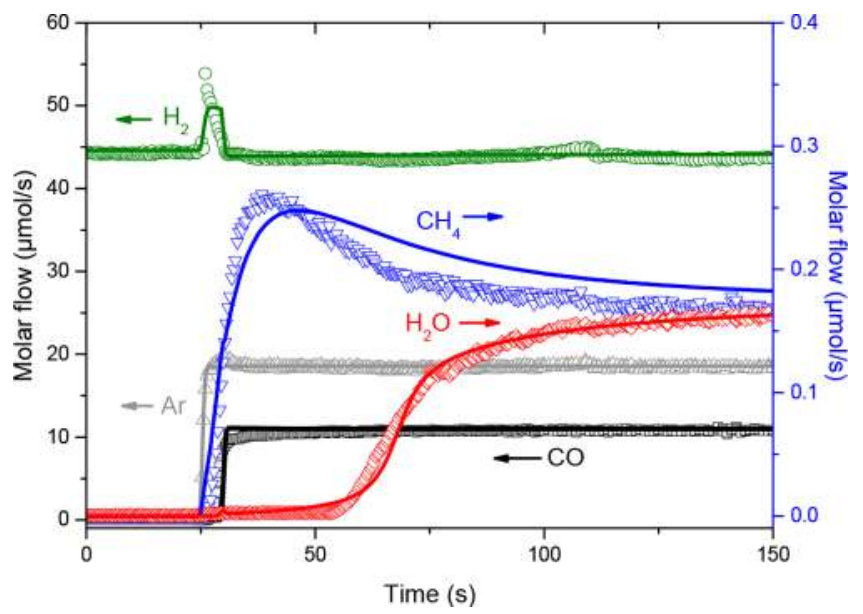

Figure 4. Step response experiment of a switch of $40 \mathrm{He} / 60 \mathrm{H}_{2}$ to 25 $\mathrm{Ar} / 60 \mathrm{H}_{2} / 15 \mathrm{CO}$ over 20 wt $\% \mathrm{Ni} / \mathrm{Al}_{2} \mathrm{O}_{3}$ at $210{ }^{\circ} \mathrm{C}$. Symbols are experimental data; lines correspond to microkinetic model simulation.

support. This was further verified by conducting the same experiment over a $10 \mathrm{wt} \% \mathrm{Ni} / \mathrm{SiC}$ catalyst. $\mathrm{SiC}$ is more hydrophobic than alumina and will have less interaction with water. As shown in Figure 5, now an initial "overshoot" in the water response is observed, while the methane response increases gradually to steady state.

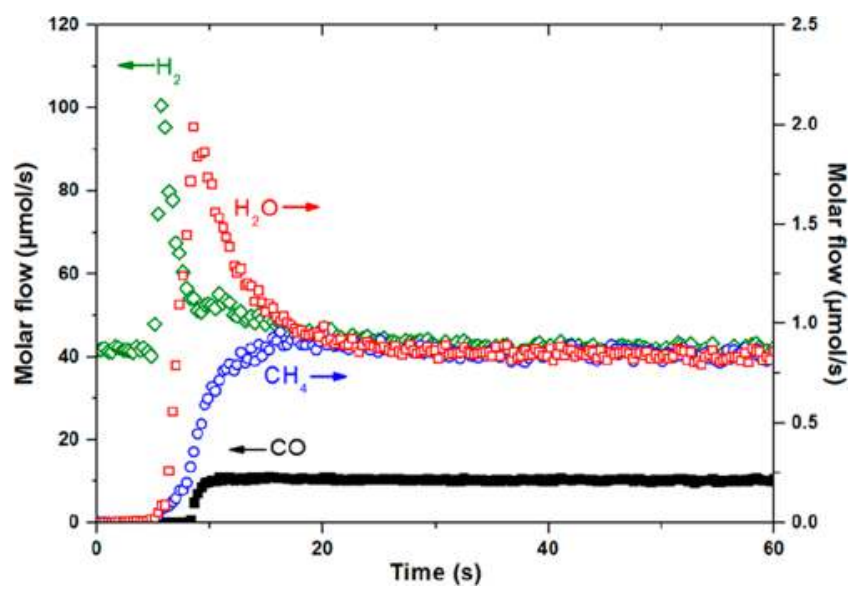

Figure 5. Step response experiment of a switch of $40 \mathrm{He} / 60 \mathrm{H}_{2}$ to 25 $\mathrm{Ar} / 60 \mathrm{H}_{2} / 15 \mathrm{CO}$ over $10 \mathrm{wt} \% \mathrm{Ni} / \mathrm{SiC}$, at $225{ }^{\circ} \mathrm{C}$.

\section{DISCUSSION}

Methane production by a two-pool parallel route, as evidenced here over $\mathrm{Ni} / \mathrm{Al}_{2} \mathrm{O}_{3}$ by SSITKA experiments, has been observed over a large number of methanation and FischerTropsch catalysts. ${ }^{35,39-44}$ Soong et al. ${ }^{32}$ were the first to analyze their data over Raney nickel catalysts in terms of a twopool parallel model. Several research groups refer to the two pools as $\mathrm{C}_{\alpha}$ and $\mathrm{C}_{\beta}{ }^{39-41}$ whereas de Pontes et al. ${ }^{42}$ report that $\mathrm{C}_{\alpha}$ corresponds to atomic carbon and $\mathrm{C}_{\beta}$ to alkyl fragments. $\mathrm{C}_{\alpha}$ is more reactive, while the $\mathrm{C}_{\beta}$ fraction increases for catalysts with a higher growth probability. Yang et al. ${ }^{41}$ proposed that the $\mathrm{C}_{\alpha}$ and $\mathrm{C}_{\beta}$ pools correspond, respectively, to $\mathrm{CH}_{2} \mathrm{O}^{*}$ and $\mathrm{CH}_{x}$ species, based on a combined kinetic and DFT study for syngas conversion over a 20 wt \% Co supported on carbon nanotubes. 
Table 3. Elementary Steps for $\mathrm{CO}$ Methanation over $20 \mathrm{wt} \mathrm{Ni} / \mathrm{Al}_{2} \mathrm{O}_{3}$ with the Corresponding Parameter Values and the Degree of Rate Control for the Methane Production at $210^{\circ} \mathrm{C}$ and $\mathrm{H}_{2} / \mathrm{CO}=4^{a}$

\begin{tabular}{|c|c|c|c|c|}
\hline Step no. & Reaction step & forward rate constant $\left(\mathrm{bar}^{-1} \mathrm{~s}^{-1}\right.$ or $\left.\mathrm{s}^{-1}\right)$ & reverse rate constant $\left(\mathrm{bar}^{-1} \mathrm{~s}^{-1}\right.$ or s $\left.\mathrm{s}^{-1}\right)$ & Degree of rate control \\
\hline 1a & $\mathrm{CO}+2 * \rightleftarrows \mathrm{CO} * *$ & $(1.8 \pm 0.25) \times 10^{3}$ & 5.4 & 0.00 \\
\hline $1 b$ & $\mathrm{CO}+* \rightleftarrows \mathrm{CO} *$ & $(2.0 \pm 0.4) \times 10^{3}$ & 5.4 & 0.00 \\
\hline 2 & $\mathrm{H}_{2}+2^{*} \rightleftarrows 2 \mathrm{H}^{*}$ & $2.0 \times 10^{4}$ & 99.9 & 0.01 \\
\hline 3 & $\mathrm{CO}^{* *}+* \rightleftarrows \mathrm{C}^{* *}+\mathrm{O}^{*}$ & $(1.5 \pm 0.25) \times 10^{2}$ & 34.3 & 0.00 \\
\hline 4 & $\mathrm{C}^{* *}+\mathrm{H}^{*} \rightleftarrows \mathrm{CH}^{*}+2^{*}$ & $1.0 \pm 0.25$ & 0.7 & 0.00 \\
\hline 5 & $\mathrm{CH}^{*}+\mathrm{H}^{*} \rightleftarrows \mathrm{CH}_{2}^{*}+*$ & $(1.1 \pm 0.2) \times 10^{2}$ & 51.8 & 0.01 \\
\hline 6 & $\mathrm{CH}_{2}^{*}+\mathrm{H}^{*} \rightleftarrows \mathrm{CH}_{3}^{*}+*$ & $1.4 \pm 0.2$ & 1.5 & 0.09 \\
\hline 7 & $\mathrm{CH}_{3}^{*}+\mathrm{H}^{*} \rightleftarrows \mathrm{CH}_{4}^{*}+2^{*}$ & $(2.4 \pm 0.45) \times 10^{2}$ & $5.1 \times 10^{-3}$ & 0.00 \\
\hline 8 & $\mathrm{CO}^{*}+\mathrm{H}^{*} \rightleftarrows \mathrm{HCO}^{*}+*$ & $0.1 \pm 0.01$ & 3.1 & 0.14 \\
\hline 9 & $\mathrm{HCO}^{*}+\mathrm{H}^{*} \rightleftarrows \mathrm{HCOH}^{*}+*$ & $2.4 \pm 0.45$ & 1.2 & 0.05 \\
\hline 10 & $\mathrm{CHOH}^{*}+* \rightleftarrows \mathrm{CH}^{*}+\mathrm{OH}^{*}$ & $2.5 \pm 0.25$ & $1.2 \times 10^{2}$ & 0.36 \\
\hline 11 & $\mathrm{O}^{*}+\mathrm{H}^{*} \rightleftarrows \mathrm{OH}^{*}+*$ & $0.1 \pm 0.02$ & 19.4 & 0.31 \\
\hline 12 & $\mathrm{OH}^{*}+\mathrm{H}^{*} \rightleftarrows \mathrm{H}_{2} \mathrm{O}^{*}+2^{*}$ & $(1.2 \pm 0.35) \times 10^{2}$ & $3.7 \times 10^{2}$ & 0.04 \\
\hline 13 & $\mathrm{H}_{2} \mathrm{O}+\# \rightleftarrows \mathrm{H}_{2} \mathrm{O} \#$ & $(5.4 \pm 0.55) \times 10^{2}$ & $2.4 \times 10^{5}$ & 0.00 \\
\hline
\end{tabular}

$a_{*}$ : Nickel surface site. \#: Alumina support site. Numbers preceded \pm by are the $95 \%$ confidence intervals. Parameters listed without a confidence interval were fixed at their value during regression analysis.

By using IR spectroscopy, Derrouiche and Bianchi ${ }^{48}$ identified both linear and bridged (or multibonded) reversibly adsorbed $\mathrm{CO}$ species with similar heats of adsorption over reduced 20 wt $\% \mathrm{Ni} / \mathrm{Al}_{2} \mathrm{O}_{3}$. The reaction mechanism of methanation over nickel catalysts has been the subject of numerous studies ${ }^{5-17,27-35}$ and are briefly summarized in ref 1 . It is generally admitted in all the proposed reaction mechanisms that reversible dissociative hydrogen and reversible molecular $\mathrm{CO}$ adsorption takes place over reduced nickel surface sites. ${ }^{5-17}$ The differences in the mechanisms given in refs 5-17 concern the different carbon species present on the surface and the nature of the dissociation of CO. Either direct $\mathrm{CO}$ dissociation into surface carbon and surface oxygen occurs or the formation of an "enol-like" $\mathrm{CH}_{x} \mathrm{O}$ intermediate has been proposed. The $\mathrm{CH}_{x} \mathrm{O}$ then dissociates into $\mathrm{CH}_{x}$ and $\mathrm{OH}_{y}$ species that are further hydrogenated into methane and water. Alstrup ${ }^{5}$ developed a microkinetic model based on direct $\mathrm{CO}$ dissociation and was able to fit the data over single nickel crystals and foils. Aparicio, ${ }^{6}$ on the other hand, developed a microkinetic model based on transient experiments over a Ni/ $\mathrm{MgO}-\mathrm{MgAl}_{2} \mathrm{O}_{4}$ catalyst, via a $* * \mathrm{CHO}$ intermediate. In an attempt to reconcile these views, we developed a microkinetic model based on direct $\mathrm{CO}$ dissociation and hydrogen assisted $\mathrm{CO}$ dissociation, through $\mathrm{HCO}^{*}$ and $\mathrm{HCOH}^{*}$ intermediates, consistent with the observed two-pool parallel methane production from SSITKA experiments. Yadav and Rinker ${ }^{34}$ already proposed a mechanism based on these two routes to explain their nonsteady-state data, but did not quantify their data, nor showed that two pools of intermediates were present on their catalyst.

Table 3 lists the elementary reactions of the microkinetic model. The only difference with the mechanisms proposed previously $^{5-17}$ is that the mechanism given in Table 3 is based on both the route for direct $\mathrm{CO}^{*}$ dissociation (step 3 ) and the formation of an "enol-like" intermediate $\mathrm{CH}_{x} \mathrm{O}$ steps (8 and 9). CO adsorption takes place as either linear ( $\left.\mathrm{CO}^{*}\right)$ or bridged or multibonded ( $\mathrm{CO}^{* *}$ ) species, as shown by IR spectroscopy. ${ }^{45}$ An asterisk * indicates a nickel surface atom, and \# indicates a site on the alumina support. The surface species do not necessarily bind through the element that is preceding the asterisk in the notation of the reaction steps in Table 3. This is especially the case for the $\mathrm{HCO}^{*}$ species, which are reported as $\mathrm{OHC}^{*}$ as well as $\mathrm{HCO}^{*} .{ }^{20}$ The bridged $\mathrm{CO}^{* *}$ undergoes direct dissociation into $\mathrm{C}^{* *}$ and $\mathrm{O}^{*}$, which are then hydrogenated to $\mathrm{CH}^{*}$ and $\mathrm{OH}^{*}$. The linear $\mathrm{CO}^{*}$ undergoes hydrogenation via $\mathrm{HCO}^{*}$ to $\mathrm{HCOH}^{*}$, which then dissociates into $\mathrm{CH}^{*}$ and $\mathrm{OH}^{*}$. Here the two parallel routes join to form methane and water through further consecutive surface hydrogenation steps. An additional step for water adsorption on the support was necessary to describe the delayed water transient response. Both the transient and SSITKA experimental data were used for parameter estimation. The SSITKA data alone were not sufficient to estimate the model parameters statistically significantly. On the other hand, the transient data alone can be fitted with a single methane production route. Fitting the SSITKA data with one single route resulted for both routes in a straight line fit of the methane decay in a semilog plot similar to that of eq 5 , as shown in Figure 3. The solid lines in Figures 2 and 4 show the microkinetic model descriptions. A good fit of the model is found, especially for the SSITKA data, but the main features of the transient responses are well captured by the model. Figure 3 compares the model to the experimental decay of the methane for the SSITKA experiment. The model shows an adequate fit of the decay, confirming the two parallel routes.

Confidence intervals in the range $10-30 \%$ were estimated as reported in Table 3. The confidence intervals were determined by regression of the SSITKA data only, except the parameter for step 13, which was determined from the nonsteady state experiment. No strong parameter correlation was observed. The highest value of 0.84 was found between the forward rate constants for steps 1a and 8 . The values of the rate constants for step 2 were obtained from independent hydrogen adsorption experiments and therefore were fixed during regression analysis. The rate parameters for the backward 
Table 4. Calculated Steady-State Surface Coverages during the SSITKA Experiment at $210^{\circ} \mathrm{C}$ and $\mathrm{H}_{2} / \mathrm{CO}=4 \mathrm{Based}$ on the Microkinetic Model

\begin{tabular}{cccccccccccc}
$\mathrm{H}^{*}$ & $\mathrm{O}^{*}$ & $\mathrm{OH}^{*}$ & $\mathrm{CO}^{* *}$ & $\mathrm{CO}^{*}$ & $\mathrm{C}^{*}$ & $\mathrm{CH}^{*}$ & $\mathrm{CH}_{2}^{*}$ & $\mathrm{CH}_{3}^{*}$ \\
$1.3 \times 10^{-3}$ & 0.16 & $4.3 \times 10^{-4}$ & 0.18 & 0.25 & $1.7 \times 10^{-2}$ & $1.7 \times 10^{-3}$ & $3.5 \times 10^{-2}$ & $2.0 \times 10^{-4}$ & $2.0 \times 10^{-2}$ & 0.17 & $\mathrm{HCOH}^{*}$ \\
\hline
\end{tabular}

steps were fixed at values determined from initial regression analysis of both SSITKA and nonsteady-state data.

Calculating the relative contribution of the two routes to the production of methane shows that $65 \%$ of the methane is produced through the hydrogen assisted route and 35\% through direct CO dissociation. DFT calculations for the dissociation of $\mathrm{CO}$ over nickel surfaces show that, in the absence of hydrogen, direct $\mathrm{CO}$ dissociation occurs over only undercoordinated sites, such as steps. ${ }^{21}$ In the presence of hydrogen, $\mathrm{CO}$ dissociation takes place through a $\mathrm{COH}$ surface intermediate and can take place over terrace sites, but is still most favorable over undercoordinated sites. ${ }^{21}$ Our results show that on supported nickel particles both routes coexist, their relative importance probably depending on the number and types of undercoordinated $\mathrm{Ni}$ sites. Table 4 gives the surface coverages during the SSITKA experiment. The total CO coverage amounts to 0.43 , while the sum of all other carboncontaining species is equal to 0.25 . The model underestimates the total $\mathrm{CO}$ coverage compared to the experimental value given in Table 1 . This might be due to a slight misfit of the $\mathrm{CO}$ response and/or the correction of the experimental data by the chromatographic effect. A significant $\mathrm{O}^{*}$ coverage is given by the model, which might be due to the underestimation of the rate of water formation. This rate is "masked" by the strong interaction of water with the alumina support. The $\mathrm{CO}^{* *}$ coverage of 0.18 corresponds well with the fraction of 0.2 of steps and edges of a truncated octahedron particle with a diameter of $5 \mathrm{~nm} .{ }^{53}$ Thus, the bridged $\mathrm{CO}$ species might be located at the steps and edges where direct $\mathrm{CO}$ dissociations are favored according to DFT studies. ${ }^{21}$

To further analyze the microkinetic model, the degree of rate control was calculated for all steps in the mechanism and given in Table 3. There is not a single rate-controlling step, but the dissociation of the $\mathrm{CHOH}^{*}$ intermediate has the highest coefficient of 0.36 , closely followed by the formation of hydroxyl species $(0.31)$. The reaction orders are 0.33 for hydrogen and -0.93 for $\mathrm{CO}$, in agreement with the reaction orders reported in the literature that range for hydrogen from 0.2 to 0.82 and for $\mathrm{CO}$ from -0.8 to 0.8 . $^{11,13}$

\section{CONCLUSIONS}

The use of different transient methods has revealed some specific features of $\mathrm{CO}$ methanation over an alumina supported nickel catalyst. In both the presence and absence of hydrogen, $\mathrm{CO}$ dissociates reversibly over the nickel catalyst with similar rates. These rates are faster than the rate for the formation of methane. SSITKA experiments show that the working catalyst is mainly covered by adsorbed $\mathrm{CO}$ species and that methane is formed through two parallel routes. Nonsteady-state experiments show an increase in methane production at high surface hydrogen coverage and a strong interaction of the alumina support with water. Based on these observations, a quantitively microkinetic model for $\mathrm{CO}$ methanation has been developed. Notably, it includes two parallel routes for methane production, one based on direct $\mathrm{CO}$ dissociation likely over edge and step sites and one through hydrogen assisted $\mathrm{CO}$ dissociation likely on terrace sites. The existence of parallel pools of $\mathrm{CHx}$ species has been observed over different $\mathrm{CO}$ hydrogenation catalysts, like iron, cobalt, and ruthenium. These catalysts are used for the synthesis of long chain hydrocarbons and are often structure sensitive. If one of these species can be linked to the desired products, proper catalyst design can then lead to higher selectivities.

\section{ASSOCIATED CONTENT}

Supporting Information

The Supporting Information is available free of charge at https://pubs.acs.org/doi/10.1021/acs.iecr.0c05885.

Evaluation of different criteria to assess the intrinsic kinetic conditions. (PDF)

\section{AUTHOR INFORMATION}

\section{Corresponding Author}

Yves Schuurman - Université de Lyon, Université Claude

Bernard Lyon 1, CNRS, IRCELYON, F-69626 Villeurbanne, France; (1) orcid.org/0000-0002-2936-0910;

Email: yves.schuurman@ircelyon.univ-lyon1.fr

\section{Authors}

Davide Lorito - Université de Lyon, Université Claude Bernard Lyon 1, CNRS, IRCELYON, F-69626 Villeurbanne, France

Pascal Fongarland - Université de Lyon, Laboratoire de Génie des Procédés Catalytiques (LGPC) UMR 5285, CNRS/CPE Lyon/UCBL, F-69100 Villeurbanne, France

\section{Notes}

The authors declare no competing financial interest.

\section{ACKNOWLEDGMENTS}

The authors would like to express their appreciation for the discussions with Enrico Tronconi on the interpretation and quantitative treatment of step-transient methanation experiments.

\section{REFERENCES}

(1) Rönsch, S.; Schneider, J.; Matthischke, S.; Schlüter, M.; Götz, M. Review on methanation - From fundamentals to current projects. Fuel 2016, 166, 276-296.

(2) Kopyscinski, J.; Schildhauer, T. J.; Biollaz, S. M.A. Production of synthetic natural gas (SNG) from coal and dry biomass - A technology review from 1950 to 2009. Fuel 2010, 89, 1763-1783.

(3) Enger, B. C.; Holmen, A. Nickel and Fischer-Tropsch Synthesis. Catal. Rev.: Sci. Eng. 2012, 54, 437-488.

(4) Khodakov, A. Y.; Chu, W.; Fongarland, P. Advances in the Development of Novel Cobalt Fischer-Tropsch Catalysts for Synthesis of Long-Chain Hydrocarbons and Clean Fuels. Chem. Rev. 2007, 107, 1692-1744.

(5) Alstrup, I. On the Kinetics of CO Methanation on Nickel Surface. J. Catal. 1995, 151, 216-225. 
(6) Aparicio, L. M. Transient Isotopic Studies and Microkinetic Modeling of Methane Reforming over Nickel Catalysts. J. Catal. 1997, $165,262-274$.

(7) Bundhoo, A.; Schweicher, J.; Frennet, A.; Kruse, N. Chemical Transient Kinetics Applied to CO Hydrogenation over a Pure Nickel Catalyst. J. Phys. Chem. C 2009, 113, 10731-10739.

(8) Fujita, S.-I.; Terunuma, H.; Nakamura, M.; Doi, T.; Takezawa, $\mathrm{N}$. Mechanisms of methanation of $\mathrm{CO}$ and $\mathrm{CO} 2$ over Ni. Ind. Eng. Chem. Res. 1991, 30, 1146-51.

(9) Fujita, S.-I.; Nakamura, M.; Doi, T.; Takezawa, N. Mechanisms of methanation of carbon dioxide and carbon monoxide over nickel/ alumina catalysts. Appl. Catal., A 1993, 104, 87-100.

(10) Mori, T.; Masuda, H.; Imai, H. Kinetics, Isotope Effects, and Mechanism for the Hydrogenation of Carbon Monoxide on Supported Nickel Catalysts. J. Phys. Chem. 1982, 86, 2753-2760.

(11) van Meerten, R. Z. C.; Vollenbroek, J. G.; de Croon, M. H. J. M.; van Nisselrooy, P. F. M. T.; Coenen, J. W. E. The kinetics and mechanism of the methanation of carbon monoxide on a nickel-silica catalyst. Appl. Catal. 1982, 3, 29-56.

(12) Coenen, J. W. E.; Van Nisselrooy, P. F. M. T.; De Croon, M. H. J. M.; Van Dooren, P. F. H. A.; Van Meerten, R. Z. C. The dynamics of methanation of carbon monoxide on nickel catalysts. Appl. Catal. 1986, 25, 1-8.

(13) Van Ho, S.; Harriott, P. The Kinetics of Methanation on Nickel Catalysts. J. Catal. 1980, 64, 272-283.

(14) Van Herwijnen, T.; Van Doesburg, H.; De Jong, W. A. Kinetics of the Methanation of $\mathrm{CO}$ and $\mathrm{CO} 2$ on a Nickel Catalyst. J. Catal. 1973, 28, 391-402.

(15) Klose, J.; Baerns, M. Kinetics of the methanation of carbon monoxide on an alumina-supported nickel catalyst. J. Catal. 1984, 85, 105-16.

(16) Hayes, R. E.; Thomas, W. J.; Hayes, T. E. A study of the nickelcatalyzed methanation reaction. J. Catal. 1985, 92, 312-26.

(17) Sehested, J.; Dahl, S.; Jacobsen, J.; Rostrup-Nielsen, J. R. Methanation of $\mathrm{CO}$ over nickel: mechanism and kinetics at high $\mathrm{H} 2$ / CO ratios. J. Phys. Chem. B 2005, 109, 2432-2438.

(18) Ge, Q.; Neurock, M. Adsorption and Activation of CO over Flat and Stepped Co Surfaces: A First Principles Analysis. J. Phys. Chem. B 2006, 110, 15368-15380.

(19) Inderwildi, O. R.; Jenkins, S. J.; King, D. A. Fischer-Tropsch Mechanism Revisited: Alternative Pathways for the Production of Higher Hydrocarbons from Synthesis Gas. J. Phys. Chem. C 2008, 112, 1305-1307.

(20) Qi, Y.; Yang, J.; Duan, X.; Zhu, Y.-A.; Chen, D.; Holmen, A. Discrimination of the mechanism of $\mathrm{CH} 4$ formation in FischerTropsch synthesis on Co catalysts: a combined approach of DFT, kinetic isotope effects and kinetic analysis. Catal. Sci. Technol. 2014, 4, 3534-3543.

(21) Andersson, M. P.; Abild-Pedersen, F.; Remediakis, I. N.; Bligaard, T.; Jones, G.; Engbæk, J.; Lytken, O.; Horch, S.; Nielsen, J. H.; Sehested, J.; Rostrup-Nielsen, J. R.; Nørskov, J. K.; Chorkendorff, I. Structure sensitivity of the methanation reaction: $\mathrm{H} 2$-induced $\mathrm{CO}$ dissociation on nickel surfaces. J. Catal. 2008, 255, 6-19.

(22) Tuxen, A.; Carenco, S.; Chintapalli, M.; Chuang, C.-H.; Escudero, C.; Pach, E.; Jiang, P.; Borondics, F.; Beberwyck, B.; Alivisatos, A. P.; Thornton, G.; Pong, W.-F.; Guo, J.; Perez, R.; Besenbacher, F.; Salmeron, M. Size-Dependent Dissociation of Carbon Monoxide on Cobalt Nanoparticles. J. Am. Chem. Soc. 2013, 135, 2273-2278.

(23) Marwood, M.; Doepper, R.; Renken, A. In-situ surface and gas phase analysis for kinetic studies under transient conditions The catalytic hydrogenation of CO2. Appl. Catal., A 1997, 151, 223-246.

(24) Burch, R.; Goguet, A.; Meunier, F. C. A critical analysis of the experimental evidence for and against a formate mechanism for high activity water-gas shift catalysts. Appl. Catal., A 2011, 409-410, 3-12.

(25) Sanchez-Escribano, V.; Larrubia Vargas, M. A.; Finocchio, E.; Busca, G. On the mechanisms and the selectivity determining steps in syngas conversion over supported metal catalysts: An IR study. Appl. Catal., A 2007, 316, 68-74.
(26) Shannon, L.; Goodwin, J. G. Characterization of Catalytic Surfaces by isotopic-transient kinetics during steady-state reaction. Chem. Rev. 1995, 95, 677-695.

(27) Happel, J.; Suzuki, I.; Kokayeff, P.; Fthenakis, V. Multiple isotope tracing of methanation over nickel catalyst. J. Catal. 1980, 65, 59-77.

(28) Biloen, P. Transient Kinetic Methods. J. Mol. Catal. 1983, 21, $17-24$.

(29) Bennett, C. O. Understanding Heterogeneous Catalysis through the Transient Method. ACS Symp. Ser. 1982, 178, 1.

(30) Underwood, R. P.; Bennett, C. O. The $\mathrm{CO} / \mathrm{H} 2$ reaction over Nickel-Alumina studied by the Transient Method. J. Catal. 1984, 86, 245-253.

(31) Walter, E.; Lecourtier, Y.; Happel, J.; Kao, J. ldentifiability and Distinguishability of Fundamental Parameters in Catalytic Methanation. AIChE J. 1986, 32, 1320-1366.

(32) Agnelli, M.; Swaan, H. M.; Marquez-Alvarez, C.; Martin, G. A.; Mirodatos, C. CO Hydrogenation on a Nickel Catalyst. II. A Mechanistic Study by Transient Kinetics and Infrared Spectroscopy. J. Catal. 1998, 175, 117-128.

(33) Otarod, M.; Happel, J.; Walter, E. Transient isotopic tracing of methanation kinetics with parallel paths. Appl. Catal., A 1997, 160, 311.

(34) Yadav, R.; Rinker, R. G. Step-Response Kinetics of Methanation over a Ni/Al203 Catalys. Ind. Eng. Chem. Res. 1992, 31, 502-508.

(35) Soong, Y.; Krishna, K.; Biloen, P. Catalyst Aging Studied with Isotopic Transients: Raney Nickel Methanation over. J. Catal. 1986, 97, 330-343.

(36) Schuurman, Y. Assessment of kinetic modeling procedures of TAP experiments. Catal. Today 2007, 121, 187-196.

(37) Berger, R. J.; Kapteijn, F.; Moulijn, J. A.; Marin, G. B.; De Wilde, J.; Olea, M.; Chen, D.; Holmen, A.; Lietti, L.; Tronconi, E.; Schuurman, Y. Dynamic methods for catalytic kinetics. Appl. Catal., A 2008, 342, 3-28.

(38) Schuurman, Y. Aspects of kinetic modeling of fixed bed reactors,. Catal. Today 2008, 138, 15-20.

(39) Van Dijk, H. A. J.; Hoebink, J. H. B. J.; Schouten, J. C. A mechanistic study of the Fischer - Tropsch synthesis using transient isotopic tracing. Part 2: Model quantification. Top. Catal. 2003, 26, $163-171$

(40) Govender, N. S.; de Croon, M. H. J. M.; Schouten, J. C. Reactivity of surface carbonaceous intermediates on an iron-based Fischer-Tropsch catalyst. Appl. Catal., A 2010, 373, 81-9.

(41) Yang, J.; Qi, Y.; Zhu, J.; Zhu, Y.-A.; Chen, D.; Holmen, A. Reaction mechanism of $\mathrm{CO}$ activation and methane formation on $\mathrm{Co}$ Fischer-Tropsch catalyst: A combined DFT, transient, and steadystate kinetic modeling. J. Catal. 2013, 308, 37-49.

(42) De Pontes, M.; Yokomizo, G. H.; Bell, A. T. A Novel Method for Analyzing Transient Response Data Obtained in Isotopic Tracer Studies of CO Hydrogenation. J. Catal. 1987, 104, 147-155.

(43) Petallidou, K. C.; Vasiliades, M. A.; Efstathiou, A. M. Deactivation of $\mathrm{Co} / \mathrm{c}-\mathrm{Al} 2 \mathrm{O} 3$ in $\mathrm{CO}$ methanation studied by transient isotopic experiments: The effect of Co particle size. J. Catal. 2020, 389, 176-194.

(44) Vasiliades, M. A.; Kalamaras, C. M.; Govender, N. S.; Govender, A.; Efstathiou, A. M. The effect of preparation route of commercial $\mathrm{Co} / \mathrm{c}-\mathrm{Al} 2 \mathrm{O} 3$ catalyst on important Fischer-Tropsch kinetic parameters studied by SSITKA and CO-DRIFTS transient hydrogenation techniques. J. Catal. 2019, 379, 60-77.

(45) Lorito, D.; Li, H.; Travert, A.; Maugé, F.; Meunier, F. C.; Schuurman, Y.; Mirodatos, C. Understanding deactivation processes during bio-syngas methanation: DRIFTS and SSITKA experiments and kinetic modeling over $\mathrm{Ni} / \mathrm{Al} 2 \mathrm{O} 3$ catalysts. Catal. Today 2018, 299, 172-182.

(46) Hindmarsh, A. C. ODEPACK, A systematized collection of ODE solvers; Elsevier: 1983.

(47) Delgado, J. M. P. Q. A critical review of dispersion in packed beds. Heat Mass Transfer 2006, 42, 279-310. 
(48) Derrouiche, S.; Bianchi, D. Heats of adsorption of the linear and bridged $\mathrm{CO}$ species on a $\mathrm{Ni} / \mathrm{Al} 2 \mathrm{O} 3$ catalyst by using the AEIR method. Appl. Catal., A 2006, 313, 208-217.

(49) Marquardt, D. W. An algorithm for least squares estimation of non-linear parameters. J. Soc. Ind. Appl. Math. 1963, 11, 431-441.

(50) Levenberg, K. A method for the solution of certain non-linear problems in least squares. Q. Appl. Math. 1944, 2, 164-168.

(51) EUROKIN spreadsheet for assessment of transport limitations in gas-solid fixed beds https://www.eurokin.org/wp-content/ uploads/webtool/EUROKIN fixed-bed html.htm (accessed October 2020).

(52) Campbell, C. T. Micro- and macro-kinetics: their relationship in heterogeneous catalysis. Top. Catal. 1994, 1, 353-366.

(53) Van Hardeveld, R.; Hartog, F. The statistics of surface atoms and surface sites on metal crystals. Surf. Sci. 1969, 15, 189-230. 